\title{
Programas de Melhoria de Processos de Software: Reflexões sob a Ótica de uma Teoria de Intervenção
}

\author{
André Felipe Lemos Santana, Hermano Perrelli de Moura
}

Centro de Informática - Universidade Federal de Pernambuco (UFPE) Caixa Postal 7851 - Cidade Universitária - 50732-970 - Recife - PE - Brazil

\{afls2, hermano\} @cin.ufpe.br

\begin{abstract}
Software Process Improvement (SPI) initiatives may be viewed as an intervention in the target organization. Research show that many success critical factors in SPI are human, social and organizational issues. An Intervention Theory in organizations may contribute significantly in understanding and dealing with such issues in SPI programs. This work presents principles of an Intervention Theory and relates them to critical factors of success in SPI found in several research works. In this way, some reflections are presented, as well as some useful prescriptive indications about conducting such programs.
\end{abstract}

Resumo. Programas de Melhoria de Processos de Software (MPS) podem ser vistos como uma intervenção na organização. Pesquisas mostram que vários dos fatores críticos de sucesso em MPS são questões humanas, sociais e organizacionais. Uma Teoria de Intervenção em organizações pode contribuir significativamente ao entendimento e tratamento destas questões em programas de MPS. Este trabalho apresenta princípios de uma Teoria de Intervenção relacionando-os a fatores críticos de sucesso em MPS apontados em diversas pesquisas. Sobre isto, busca realizar algumas reflexões e indicar prescrições úteis na condução destes programas.

\section{Introdução}

Desenvolvimento de software é uma atividade crítica em nossa sociedade atual na medida em que esta depende cada vez mais de software em grande parte dos produtos e serviços que consome [Fuggetta, 2000]. Porém, aplicações de software são produtos complexos, difíceis de desenvolver e testar. Em função do atual estado de produção destas aplicações, pode-se observar muito freqüentemente, que elas exibem comportamentos inesperados e indesejados que podem causar sérios problemas em muitas situações. Além disso, as empresas de desenvolvimento de software operam num mercado muito dinâmico, sob pressão de restrições de tempo, custo e exigência por qualidade. Relatório do Standish Group [The Standish Group International Inc., 2001] sobre a resolução de projetos de software da indústria norte-americana, apontou que, no ano 2000 , apenas $28 \%$ deles obtiveram o sucesso esperado, $49 \%$ foram concluídos com estouro de prazo, orçamento e com menos funcionalidades que o previsto, e $23 \%$ falharam completamente, pois sequer foram concluídos.

Nos últimos 20 anos, estas questões têm motivado vários projetos dedicados à criação de modelos de qualidade e métodos para melhoria de processos de software 
$\left(\mathrm{MPS}^{1}\right)$, visando obter mais controle sobre os processos e mais competitividade para as organizações que produzem software. Estes modelos e métodos sugerem uma série de etapas a serem atingidas de forma a melhorar a qualidade de um processo de software. Basicamente, eles indicam como realizar o "processo de melhorar um processo" [Fuggetta, 2000]. Alguns dos modelos mais conhecidos são: CCM (Capability Maturity Model) [Paulk et ali, 1993], CMMI (Capability Maturity Model Integration) [CMU/SEI, 2001] e SPICE (Software Process Improvement and Capability dEtermination) [SPICE, 2005].

[Abrahamsson, 2000] cita vários trabalhos relatando que o investimento em melhoria de processo tem trazido benefícios significativos para o negócio, como: melhoria da qualidade do produto, redução do tempo de lançamento do produto no mercado, melhor produtividade, maior flexibilidade organizacional e satisfação dos clientes. Citando um relatório do Data \& Analysis Center for Software (DACS) de 1996, reporta que programas bem sucedidos de MPS reduziram o número de defeitos nos produtos entregues aos clientes em 95\%, reduziram erros de cronograma de desenvolvimento de software em $71 \%$, e incrementaram a produtividade/dia em termos de linhas de código ou pontos de função em $222 \%$. Relata ainda, dado do SEI (Software Engineering Institute) reportando um retorno médio de 1:5 do investimento em programas de MPS bem sucedidos. Embora estes resultados pareçam atrativos, [Abrahamsson, 2002] cita estudo relatando que em torno de dois terços dos programas de MPS falharam, ou atenderam insuficientemente às expectativas.

Pesquisamos diversos estudos que levantam os principais fatores que influenciam o nível de sucesso de iniciativas de MPS. Todavia, não encontramos pesquisas que tratem da influência de teorias de intervenção que estão subjacentes à ação prevista nestes programas. Na seção seguinte deste texto, é exibido um resumo de alguns relatos de pesquisa sobre fatores de sucesso mais impactantes em programas de MPS. Em seguida, são apresentados alguns fundamentos de uma Teoria de Intervenção nas organizações, que mais adiante, servem de base para algumas reflexões sobre programas de MPS sob a ótica dos conceitos descritos. Posteriormente, à luz destas reflexões e dos conceitos, são feitas algumas prescrições úteis a intervenções de MPS. Finalmente, são feitas algumas considerações finais a título de conclusão e também identificação de oportunidades para trabalhos futuros nesta abordagem.

\section{Alguns Relatos de Pesquisas sobre Fatores de Sucesso em MPS}

Vários estudos tais como [Goldenson e Herbsleb, 1995], [El Emam et Ali, 1998], [Stelzer e Mellis, 1998] e [Rainer e Hall, 2000] podem ser encontrados envolvendo a análise de fatores de sucesso em MPS. A Tabela 1 destaca os fatores mais importantes, segundo estes trabalhos.

Antigamente, autores da área costumavam associar os problemas de insucesso a fatores como planejamento e organização pobres das atividades de MPS [Abrahamsson, 2002]. Mais recentemente, conforme podemos observar na Tabela 1, surge uma crescente quantidade de pesquisas explicando estas falhas em termos de maior influência de fatores humanos, sociais e organizacionais ("soft factors").

\footnotetext{
${ }^{1}$ Do inglês SPI - Software Process Improvement.
} 
Dentre estes fatores, vários estudos citados por [Abrahamsson, 2000 e 2002] têm dado especial destaque ao tema comprometimento. Este autor relata que a prática e a literatura em MPS, raramente têm concordado tão consistentemente sobre a importância de um conceito específico, como no caso de comprometimento. Pesquisas dão conta de que, considerando um programa de MPS bem planejado, comprometimento em todos os níveis da organização, tem sido apontado como um dos fatores mais importantes para determinar se uma iniciativa deste tipo irá ou não, ser bem sucedida.

\begin{tabular}{|c|c|c|c|c|}
\hline Fator Crítico em MPS & Goldenson & El Emam & Stelzer & Rainer \\
\hline Comprometimento da gerência sênior & ! & - & - & \\
\hline Metas de MPS claras e relevantes & - & - & - & \\
\hline $\begin{array}{l}\text { Atribuição de resposabilidade clara e } \\
\text { recompensada para MPS }\end{array}$ & - & - & & \\
\hline Envolvimento do staff & - & - & - & \\
\hline $\begin{array}{l}\text { Colaboradores de MPS reconhecidos e } \\
\text { respeitados }\end{array}$ & - & - & & \\
\hline Tempo e recursos do staff & - & - & & \\
\hline Criação de times de ação em processos & & - & & \\
\hline Agentes de mudança e líderes de opinião & & & - & \\
\hline $\begin{array}{l}\text { Encorajamento da comunicação e } \\
\text { colaboração }\end{array}$ & & & - & \\
\hline Gerenciamento do projeto de MPS & & & - & \\
\hline Promoção de melhor entendimento & & & - & \\
\hline Estabilizar processos modificados & & & - & \\
\hline "Costura" de inciativas de melhoria & & & - & \\
\hline $\begin{array}{l}\text { "Descongelamento" (desenrijecimento) } \\
\text { da organização }\end{array}$ & & & - & \\
\hline Treinamento e mentoria & & & & - \\
\hline Revisões & & & & - \\
\hline Padrões e procedimentos & & & & - \\
\hline Staff experiente & & & & - \\
\hline Inspeções & & & & - \\
\hline Pertença interna dos processos & & & & - \\
\hline
\end{tabular}

Tabela 1. Fatores críticos de sucesso em MPS.

De uma forma geral, este e outros fatores humanos tendem a impactar fortemente as iniciativas que envolvem mudanças nas organizações. Estas iniciativas podem ser vistas como uma intervenção na organização, isto é, um programa de ação deliberada que muda o curso rotineiro da organização, visando um objetivo. Torna-se então importante, refletir sobre questões como: o que é intervir numa organização? Que aspectos podem estar implicitamente em questão nos modelos normativos de MPS, utilizados para ação de mudança, mas que não são tratados por eles? A seção seguinte aborda algumas dessas questões.

\section{Teoria de Intervenção nas Organizações}

De acordo com [Argyris, 1970], intervir é entrar num sistema de relações em andamento, e aproximar-se de pessoas ou grupos com o propósito de ajudá-los. 
Considerando um contexto organizacional, normalmente, esta ajuda está associada à compreensão e solução dos problemas da organização. Não necessariamente isto significa uma ação reativa em resposta a situações indesejadas já ocorridas, pode ser também uma atitude pró-ativa em relação a um cenário desejado. $\mathrm{O}$ conceito aqui é utilizado de uma forma ampla, e podemos dizer que uma intervenção é tão mais "organizacional", quanto mais abrangente é sua influência nas estruturas e cultura da organização como um todo, e não só em certos aspectos específicos. Este tipo de trabalho normalmente está associado à atividade de consultoria, e o(s) interveniente(s) responsáveis por guiar os trabalhos, aos consultores. Todavia, os intervenientes podem ser pessoas externas ou internas à organização. Para ilustrar alguns exemplos conhecidos de intervenções de natureza distinta, podem ser citados: a implantação de um programa de Qualidade Total, o desenvolvimento e implantação de um planejamento estratégico, um programa de melhoria das relações inter-pessoais na altaadministração, ou uma iniciativa de MPS numa empresa de desenvolvimento de software, caso que particularmente nos interessa mais aqui.

Embora possam ser vários a natureza, os motivos e objetivos específicos de uma intervenção, [Argyris, 1970] sustenta que devem ser três as tarefas primárias envolvidas no processo:

- Gerar informação válida ${ }^{2}$ e útil $^{3}$ sobre o objeto da intervenção (objetivos, contexto, andamento da intervenção);

- Gerar escolha livre $\mathbf{e}^{4}$ e informada $\mathbf{a}^{5}$ sobre os destinos da intervenção.

- Gerar comprometimento interno ${ }^{6}$ com as decisões da intervenção.

A relação entre estas tarefas primárias pode ser compreendida como uma seqüência de causalidade cíclica de acordo com o diagrama mostrado na Figura 1.

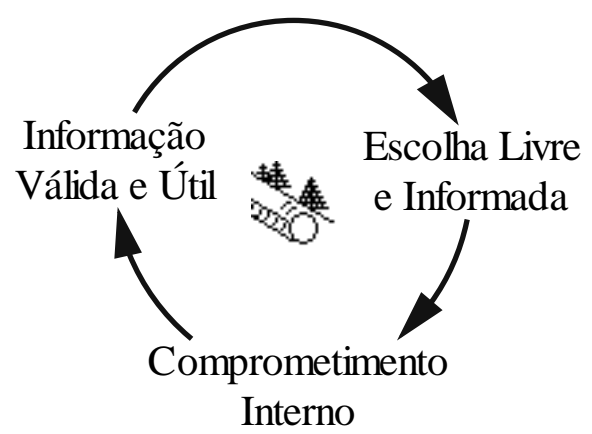

Figura 1. Ciclo de relações causais entre as tarefas primárias.

Por este diagrama, observamos que a geração de informação válida e útil sobre o objeto da intervenção favorece o processo de escolha livre e informada sobre os destinos da intervenção, que por sua vez tende a gerar nos participantes o comprometimento interno com as escolhas feitas por eles próprios. $\mathrm{O}$ comprometimento

\footnotetext{
${ }^{2}$ Que pode ser testada e validada publicamente.

${ }^{3}$ Que tem potencial de ser utilizada na intervenção.

${ }^{4}$ Os participantes tomam decisões relativas à intervenção de forma livre e sem coerção ou manipulação das escolhas pelo interveniente.

${ }^{5}$ As escolhas são feitas pela exploração de opções fundamentadas em informações válidas.

${ }^{6}$ Interno, no sentido de que o estímulo principal para comprometimento vem de uma motivação interna da pessoa, e não por uma pressão externa.
} 
interno por sua vez, realimenta o ciclo de reforço "virtuoso", estimulando mais geração de informação válida e útil. Por outro lado, este mesmo diagrama pode também explicar o efeito negativo sobre o sistema de intervenção, que ocorre quando uma (ou mais) das tarefas primárias é relegada a segundo plano: suponhamos, por exemplo, que a intervenção não esteja enfatizando devidamente a geração de informação válida e útil sobre o processo em curso, então, isto tenderá a gerar menos capacidade de escolha livre e informada que por sua vez dificultará o comprometimento interno dos participantes. Finalmente, isto fará com que eles tenham menos estímulo à geração de informação válida e útil, fechando assim o que seria um ciclo de reforço "vicioso" que prejudica o sucesso da intervenção.

É importante observar que estas tarefas primárias, não são um conjunto de ações específicas bem definidas, que ocorrem como etapas seqüenciais de uma intervenção. Antes, elas são diretrizes para a ação dos intervenientes e dos clientes que podem ocorrer paralelamente entre si e devem ser levadas em conta ao longo de todas as ações realizadas numa intervenção.

Para [Argyris, 1970], estas diretrizes são guias de ação fundamentais para o sucesso de uma intervenção e o papel principal de um interveniente é zelar por estas tarefas primárias. Elas podem inclusive, ser utilizadas como critérios por parte de um interveniente para decidir sobre, se irá ou não, tomar parte numa intervenção e ajudar um cliente. Ele poderá fazer isso realizando um pré-diagnóstico para analisar a capacidade do cliente de se adequar às tarefas primárias. Da mesma forma, uma organização-cliente suficientemente consciente, poderia utilizar este mesmo critério para selecionar um interveniente, nesse caso, observando se seu método de trabalho enfatiza estas tarefas primárias.

Muitos outros conceitos relativos ao sistema em intervenção podem ser listados como importantes para o processo [Argyris, 1970] [Argyris e Schön, 1974]. Todavia, considerando as limitações de espaço e dos objetivos deste texto, priorizaremos, nas seções seguintes, comentários sobre os conceitos relativos às tarefas primárias, por serem mais internos à atividade de intervenção em si e serem suficientemente potentes para as reflexões que fazemos mais adiante.

\subsection{Geração de Informação Válida e Útil}

Vale destacar que a tarefa primária de geração de informação válida e útil, dentre as três citadas é provavelmente aquela que o interveniente tem mais influência e controle através de seus métodos de intervenção. Ela pode ser associada mais formalmente à atividade de pesquisa diagnóstica sobre a situação em intervenção. Uma pesquisa diagnóstica é geralmente uma das primeiras etapas de um processo de intervenção que irá subsidiar a ação nas demais etapas. Em se tratando de MPS, naturalmente nas etapas iniciais do programa, é aconselhável a realização de um diagnóstico sobre, por exemplo, a situação atual dos processos de software utilizados, entre outros fatores.

Todavia, para [Argyris, 1970] a tarefa primária de geração de informação válida e útil é uma diretriz de ação crucial a ser seguida em toda e qualquer etapa, para além da etapa formal de diagnóstico, pois ela subsidia com dados o processo de monitoramento da intervenção. Como método de realização desta diretriz, este autor faz várias considerações sobre sua preferência pela pesquisa orgânica, cuja aplicação é mais comum entre os pesquisadores das ciências sociais. Entretanto, para efeito das reflexões 


\section{Simpósio Brasileiro de Qualidade de Software}

mais amplas deste texto, consideramos válidos outros métodos que atendam aos objetivos desta diretriz, ou seja: gerar informação sobre o contexto da intervenção, que seja válida e útil para a ação.

\subsection{Geração de Escolha Livre}

Para [Argyris, 1970], há apenas duas condições em que a escolha livre pode ser subenfatizada (juntamente com a geração de informação válida e útil) em função de uma estratégia mais diretiva e unilateral por parte do interveniente, na qual ele fornece as informações e induz mais diretamente as escolhas do cliente:

a) Quando não envolve o sentimento de competência do cliente (por exemplo, em questões técnicas que o cliente tenha pouco, ou nenhum domínio).

b) Quando o sistema-cliente estiver em extremo perigo e sentir-se incapacitado para a ação (mesmo assim, o interveniente deve utilizar a estratégia diretiva como uma estratégia temporária, reconhecendo que o comprometimento do cliente será extrínseco).

Vale comentar que a situação (a) acima, raramente será o caso em MPS, tendo em vista que a equipe de desenvolvimento de software geralmente possui algum grau de domínio ou capacidade de avaliação crítica, em relação a métodos de trabalho em sua área. Eventualmente, considerando o objetivo de atender a modelos normativos de MPS, poderão acontecer casos em que os clientes, por falta de experiência na situação específica, sintam dificuldades de escolher entre novos modelos de processos de software e queiram transferir esta escolha para o interveniente. Todavia, o interveniente deverá ter consciência que atender a estes anseios é uma estratégia arriscada, tendo em vista que o comprometimento do cliente com a escolha tenderá a ser extrínseco. Em situações assim, seria aconselhável gerar mais informação válida e útil para o cliente sobre as opções de escolha disponíveis. Caso haja possibilidade, uma alternativa interessante seria, por exemplo, o interveniente conduzir pequenas experiências com o cliente utilizando as próprias opções de processos indicadas. Desta forma, o cliente poderia desenvolver um melhor referencial de escolha em relação às opções, e com a ajuda do interveniente propor inclusive uma adaptação destas opções à sua realidade. Outra alternativa, possivelmente mais simples de geração de informação válida e útil para esta situação, seria conduzir estudos de caso referentes a organizações em condição semelhante a do cliente.

Em relação à situação (b) anteriormente citada, certamente este seria um caso ainda mais raro em MPS, visto que um sistema-cliente que esteja com sua saúde seriamente ameaçada necessitaria de outro tipo de intervenção em primeira instância.

\subsection{Comprometimento}

Uma definição comumente encontrada para comprometimento é a definida pelo CMM: "Commitment - a pact that is freely assumed, visible, and expected to be kept by all parties" [Olson et ali, 1994]. Entretanto, embora importante, este tipo de pacto explícito é apenas um lado do conceito de comprometimento [Abrahamsson, 2000]. Citando outras referências, este autor conceitua comprometimento de uma forma mais ampla, como um "estado psicológico de vínculo que define o relacionamento entre uma pessoa e uma entidade". Este relacionamento pode ser visto em termos de vários componentes [Abrahamsson, 2002]: 


\section{Simpósio Brasileiro de Qualidade de Software}

- Foco: define o objeto ao qual um indivíduo estabelece o vínculo. Pode ser, por exemplo: a organização, um projeto específico, um esforço de MPS ou a carreira profissional.

- Força: define o quanto o indivíduo está vinculado ao foco do comprometimento. Varia em função do significado pessoal associado ao foco do comprometimento.

- Termos: define o que o indivíduo precisa fazer ou cumprir para com o foco do comprometimento. É um pacto implícito ou explícito (um contrato, por exemplo).

- Durabilidade: diz respeito à duração do vínculo do indivíduo com o foco do comprometimento. Pode ser temporário (um projeto, por exemplo), ou duradouro (a carreira profissional, por exemplo).

- Nível: pode envolver o vínculo de um indivíduo, grupo ou organização como um todo, com o objeto do comprometimento.

- Forma: em relação à natureza do vínculo com o foco, o comprometimento pode ser:

- Afetivo: refere-se ao vínculo, envolvimento e identificação intrínseca com a entidade em foco (o indivíduo "gosta" do foco).

- Normativo: reflete o sentimento de obrigação para com a entidade em questão. É influenciado pelo sistema normativo da instituição.

- De Continuidade: refere-se à consciência sobre os custos associados a abandonar a entidade em questão. É influenciado pelo sistema de recompensa da organização.

É possível que, para um mesmo indivíduo em relação a um dado foco, haja as três formas de comprometimento, porém destas, a mais desejável é a afetiva [Abrahamsson, 2000], por não depender de fatores extrínsecos à relação indivíduoentidade. Numa dada situação, se a principal forma é a normativa, o comprometimento pode ser perdido à medida que haja menos pressão normativa sobre o indivíduo, ou mesmo excesso de pressão normativa (caso em que a pessoa, por não suportar a pressão, prefere romper com o sistema). Se a principal forma é a de continuidade (por exemplo, em função de premiação através de um sistema de recompensas), o comprometimento pode diminuir se sua base motivacional for modificada. Pode-se observar que a forma afetiva citada por [Abrahamson, 2000] aproxima-se do que [Argyris, 1970] denomina como comprometimento interno, o que reforça que esta é a forma mais desejável no contexto de uma intervenção.

\subsection{Intervenções quanto ao Grau de Inovação e Flexibilidade}

Quanto ao grau de inovação e flexibilidade no processo de intervenção, [Argyris, 1970] classifica estas iniciativas em três tipos:

a) Aquelas que utilizam modelos já existentes, baseados em um conjunto de conhecimentos e experiências em métodos para lidar com problemas já conhecidos, e comuns a diferentes tipos de cliente. Um exemplo possível no campo de MPS pode ser a implantação do modelo CMMI baseado em níveis de 


\section{Simpósio Brasileiro de Qualidade de Software}

maturidade, no qual os macro-objetivos das melhorias já estão pré-definidos pelo modelo.

b) Aquelas que utilizam modelos já existentes de uma forma mais flexível buscando um arranjo criativo do conhecimento existente, eventualmente introduzindo algumas inovações. Para exemplificar, no campo de MPS, um modelo como o CMMI "contínuo" parece ser mais adequado a este tipo de abordagem.

c) No terceiro tipo, que é mais raro, os recursos do sistema-cliente e os do interveniente são colocados juntos para conduzir uma intervenção que ajude o cliente a compreender a natureza dos seus problemas e contribua para a teoria básica da atividade de intervenção. O objetivo é ajudar o sistema-cliente e simultaneamente desenvolver novos modelos conceituais, que ajudem a explicar tanto aquele caso em particular como outros que possam ser identificados no futuro. Em MPS, equivaleria à criação de um modelo totalmente gerado a partir do diagnóstico sobre o sistema-cliente em questão, sem recorrer a outros modelos. Este último tipo é certamente mais comumente originado no ambiente acadêmico.

O primeiro tipo de intervenção é, provavelmente, o tipo mais utilizado pelos intervenientes, por isso tem como vantagem envolver métodos mais testados e, portanto, um resultado mais previsível. Ele é especialmente útil quando há pouco tempo e recursos para adaptações. Todavia, há a desvantagem de que esta prática tende a influenciar o interveniente a ver, sem se dar conta, todos os problemas dos clientes em termos desse seu repertório de soluções pré-concebidas. O segundo tipo tem como vantagem a possibilidade de uma melhor adaptação a certas necessidades do cliente e à experimentação de alguma inovação útil ao modelo. Ele tende a ser possível quando o sistema-cliente tem disponíveis um tempo e recursos adequados, um estado de saúde já existente que permita a experimentação, e um interveniente capaz de perceber apropriadamente o potencial do sistema. A principal desvantagem é um maior nível de risco em relação ao primeiro tipo. O terceiro tipo tem como vantagens mais evidentes uma possível melhor adequação às necessidades dos clientes e uma maior possibilidade de geração de inovações para o próprio campo da intervenção. As maiores desvantagens são um maior risco e maior nível de exigência sobre a competência do interveniente na condução diagnóstica e na intervenção como um todo. Há ainda o risco de reduzir o cliente a ser um sujeito de experimentação, e de que o interveniente demore na oferta da ajuda (porque ele está tentando contribuir para o conhecimento básico).

Embora [Argyris, 1970] seja claramente adepto, preferencialmente, ao terceiro tipo acima, vale ressaltar que ele preconiza que a atividade de pesquisa deveria estar sempre presente, em algum grau, em qualquer um dos tipos de intervenção, e ao longo de todas as suas fases (não apenas na fase diagnóstica). Isto é uma estratégia para geração de informação válida útil sobre a intervenção em questão e também sobre o próprio campo de pesquisa em intervenção.

\section{Reflexões sobre programas de MPS sob a ótica de uma teoria de Intervenção Organizacional}

Iniciativas em MPS parecem se enquadrar na categoria típica de intervenções em que [Argyris, 1970] preconiza como sendo fundamentais as tarefas primárias de geração de 


\section{Simpósio Brasileiro de Qualidade de Software}

informação válida, escolha livre e informada, e comprometimento interno. Na Tabela 2 apresentamos o conjunto de fatores críticos apresentados anteriormente na Seção 2, relacionando-os, quando possível, às três tarefas primárias mencionadas.

\begin{tabular}{|c|c|c|c|c|}
\hline \multirow[t]{2}{*}{ Fator Crítico em MPS } & \multicolumn{3}{|c|}{ Relação direta com as tarefas primárias } & \multirow[t]{2}{*}{ Comentário explicativo } \\
\hline & $\begin{array}{l}\text { Informação } \\
\text { Válida e Útil }\end{array}$ & $\begin{array}{c}\text { Escolha } \\
\text { Livre }\end{array}$ & $\begin{array}{l}\text { Comprometi- } \\
\text { mento Interno }\end{array}$ & \\
\hline $\begin{array}{l}\text { Comprometimento da gerência } \\
\text { sênior }\end{array}$ & Sim & Sim & Sim & - \\
\hline Metas de MPS claras e relevantes & $\operatorname{Sim}$ & - & - & $\begin{array}{l}\text { Clareza necessita de } \\
\text { geração de informação }\end{array}$ \\
\hline $\begin{array}{l}\text { Atribuição de resposabilidade clara } \\
\text { e recompensada para MPS }\end{array}$ & $\operatorname{Sim}$ & - & - & Idem acima \\
\hline Envolvimento do staff & Sim & $\mathrm{Sim}$ & $\mathrm{Sim}$ & - \\
\hline $\begin{array}{l}\text { Colaboradores de MPS } \\
\text { reconhecidos e respeitados }\end{array}$ & - & - & $\operatorname{Sim}$ & $\begin{array}{l}\text { O reconhecimento às } \\
\text { pessoas depende do } \\
\text { compromisso com o } \\
\text { programa }\end{array}$ \\
\hline Tempo e recursos do staff & - & - & Sim & - \\
\hline $\begin{array}{l}\text { Criação de times de ação em } \\
\text { processos }\end{array}$ & - & Sim & - & $\begin{array}{c}\text { Prioritariamente este time } \\
\text { deve ser de voluntários }\end{array}$ \\
\hline $\begin{array}{l}\text { Agentes de mudança e líderes de } \\
\text { opinião }\end{array}$ & $\operatorname{Sim}$ & $\operatorname{Sim}$ & - & - \\
\hline $\begin{array}{l}\text { Encorajamento da comunicação e } \\
\text { colaboração }\end{array}$ & - & - & Sim & - \\
\hline Gerenciamento do projeto de MPS & - & - & Sim & - \\
\hline Promoção de melhor entendimento & $\operatorname{Sim}$ & - & - & $\begin{array}{c}\text { Informação é condição } \\
\text { para o entendimento }\end{array}$ \\
\hline Estabilizar processos modificados & $\operatorname{Sim}$ & - & Sim & - \\
\hline "Costura" de inciativas de melhoria & - & - & Sim & - \\
\hline $\begin{array}{l}\text { "Descongelamento" (desenrijeci- } \\
\text { mento) da organização }\end{array}$ & $\operatorname{Sim}$ & $\operatorname{Sim}$ & $\operatorname{Sim}$ & - \\
\hline Treinamento e mentoria & - & - & Sim & $\begin{array}{c}\text { Mentoria em MPS } \\
\text { depende do compromisso } \\
\text { do Mentor e do Treinando }\end{array}$ \\
\hline Revisões & $\operatorname{Sim}$ & - & - & - \\
\hline Padrões e procedimentos & - & - & Sim & $\begin{array}{l}\text { Padrões e procedimentos } \\
\text { só são seguidos quando há } \\
\text { compromisso com eles }\end{array}$ \\
\hline Staff experiente & - & - & - & - \\
\hline Inspeções & Sim & & & - \\
\hline Pertença interna dos processos & - & - & Sim & - \\
\hline
\end{tabular}

Tabela 2. Fatores críticos de sucesso em MPS relacionados às tarefas primárias.

$\mathrm{Na}$ Tabela 2, observa-se ainda que a tarefa primária de comprometimento interno é a mais facilmente relacionável aos fatores críticos de sucesso relatados em MPS, entretanto, cabe ressaltar que dentre as tarefas primárias, esta é a que o interveniente possui menos influência direta, já que comprometimento interno depende de uma decisão pessoal dos participantes. De acordo com [Argyris, 1970], a estratégia básica 
para atingi-la, deve ser justamente proporcionar geração de informação válida e útil, e escolha livre e informada. Contudo o comprometimento interno tem a vantagem de poder ser observável na ação das pessoas e, portanto, é um indicador fundamental, para monitoramento de uma intervenção.

De acordo com [Fugetta, 2000], iniciativas de MPS deveriam levar mais em conta o que outras disciplinas e pesquisadores já descobriram sobre qualidade e melhoria de processos, pois os métodos relacionados à tecnologia e processos de software ignoram ou apenas consideram superficialmente as contribuições de cientistas organizacionais. Portanto, correm os riscos de ignorar questões importantes que podem ocupar um papel crítico em iniciativas de melhorias. Por exemplo, muitas das indicações sugeridas pelo CMM têm foco apenas em aspectos de engenharia. Todavia, a implementação bem sucedida desses fatores requer, geralmente, uma reconsideração mais profunda sobre a organização que está realizando estas atividades. Este tipo de implicação é tratada inadequadamente pela maioria dos modelos de MPS.

Frequentemente a abordagem para tratamento dos problemas de processos de software é considerar que a dificuldade está na inadequação dos métodos (há uma ampla predominância de uma visão técnica). O "remédio" usual é buscar melhorá-los, tornálos mais sofisticados. Porém se a dificuldade residir na interpretação do problema estas iniciativas podem até piorá-los (adicionando mais complexidade aos processos, por exemplo). Um novo enquadramento dos problemas privilegiando aspectos sociais e organizacionais pode ser o mais indicado [Woolgar, 1994].

Uma outra fonte de problemas que merece reflexão para os profissionais de MPS é o fato de que nenhum método é genuinamente à prova de falhas [Button e Sharrock, 1994]. Há sempre um limite para a extensão do que pode ser feito pelos engenheiros de processos em termos de design de procedimentos de trabalho, sem que isso envolva a dependência do "bom senso" daqueles que terão efetivamente que seguir o procedimento em seu trabalho diário. Isto é assim porque, por mais bem definido que seja um método ou procedimento, ele reflete um conjunto de recomendações que precisam ser reinterpretadas e adaptadas pelos profissionais que os estão aplicando em seu trabalho. Sobre este particular, a atividade de desenvolvimento de software mesmo quando utiliza processos padronizados é raramente uma simples seqüência mecânica de passos que ocorrem sempre da mesma forma independente da realidade em questão. Em geral, cada novo projeto de desenvolvimento envolve diferenças de contexto em relação a projetos anteriores quanto ao domínio da aplicação, problemas a serem resolvidos na organização-cliente, ou mesmo quanto a mudanças na equipe de desenvolvimento. Por isto, este passo interpretativo e adaptativo dos profissionais para utilização na prática de uma metodologia ou procedimento é uma necessidade constante nesta atividade. Ou seja, parte do esforço em desenvolvimento de software que usa métodos definidos consiste em fazer os próprios métodos funcionarem na prática [Button e Sharrock, 1994].

Além disso, como muitos dos processos de software envolvem situações de interação entre os desenvolvedores entre si, com os gerentes e também com os clientes, estas questões abrem a possibilidade para a ocorrência do que [Argyris e Schön, 1974] chamam de "zonas indeterminadas da prática". Estas são situações em que a problemática gira em torno de conflito de valores, interesses e atitudes, onde a incerteza 
e a singularidade escapam à "lente de análise" da racionalidade técnica prevista nas metodologias e processos em questão.

Exemplificando como as teorias em uso sobre MPS podem tratar superficialmente aspectos não técnicos, podemos citar algumas concepções que, segundo [Abrahamson, 2000], são limitadas e carecem de base científica, mas que estão geralmente implícitas em modelos como o CMM [CMU/SEI, 1993] e na ação dos profissionais da área, em relação ao conceito de comprometimento:

- A noção de comprometimento como um construto singular (contrapondo esta compreensão, na Seção 3.3 deste texto foram apresentados vários componentes importantes para entendimento dos fenômenos relativos ao conceito de comprometimento).

- A crença de que o comprometimento cresce de forma linear em relação aos estímulos para seu desenvolvimento (Abrahamson argumenta que não há evidência científica disto).

- A crença na controlabilidade do processo de comprometimento (verifica-se que este é um processo, no máximo, influenciável, mas não controlável).

- A premissa de que um alto nível de comprometimento é sempre útil (verifica-se que isso não necessariamente é sempre verdade: o foco do comprometimento pode tornar-se um problema. Por exemplo: um certo engenheiro de software, por ter participado ativamente da definição de um dado processo, pode estar altamente comprometido com ele, mesmo que este processo esteja trazendo problemas à equipe. Nesse caso, este profissional tenderá a resistir à modificações no processo).

Em um outro exemplo prático do risco da superficialidade, podemos verificar como o modelo CMMI [CMU/SEI, 2001] trata a questão da participação, que ele mesmo alega que é uma questão crítica para o sucesso de certas atividades preconizadas no modelo. Diz o documento:

"The identification of promising incremental and innovative improvements should involve the participation of an empowered workforce aligned with the business values and objectives of the organization.” (página 52)

Posteriormente o documento preconiza:

"1. Promote an environment (created as part of project management) that encourages employee participation in identifying and reporting quality issues [PA145.IG101.SP101.SubP101]" (página 178)

E mais ainda:

"Successful implementation of improvements requires participation in the process definition and improvement activities by process owners, those performing the process, and support organizations. [PA152.IG102.N101] “ (página 318)

Podemos então analisar nesse caso que, embora o documento faça de fato alegações importantes sobre a necessidade da participação, criação de ambiente apropriado para participação, e decisão coletiva, não será encontrada em suas 707 páginas, qualquer aprofundamento sobre quais são as características de tal ambiente, nem de como ele pode ser criado. Nem há tampouco referência à fonte externa para 


\section{Simpósio Brasileiro de Qualidade de Software}

aprofundamento do assunto. Pode-se concluir então, sobre estas alegações do referido documento, que:

- elas parecem estar baseadas em conhecimento de senso comum, porém sem base científica testada;

- as pessoas que as utilizam, com base apenas no modelo em questão, podem não estar suficientemente conscientes sobre com o que estão lidando, e consequentemente,

- elas podem estar lidando para com este assunto muito mais como um elemento de discurso, do que algo que realmente são capazes de realizar na prática, já que por desconhecimento, podem não dispor de estratégias adequadas.

Evidentemente, em muitas situações de intervenção de MPS pode ocorrer que haja intervenientes suficientemente habilidosos e experientes, que baseados em seu conhecimento tácito, somado a uma organização-cliente igualmente madura e com alto grau de prontidão para mudança, venham a desenvolver intervenções bem sucedidas nestes aspectos. Mas certamente, haverá um outro número igual ou maior de situações em que estas questões podem trazer muitos mal-entendidos entre os participantes.

Com base em [Argyris e Schön, 1974] podemos citar que um ambiente propício à participação genuína, dentre outras características, é aquele que é criado quando as pessoas possuem uma conversação eficaz. Esta eficácia envolve a habilidade das pessoas em comunicarem-se sempre se referindo a dados observáveis ou quando isso não é possível, testando suas inferências publicamente e explicitando seus pressupostos, de forma a possibilitar uma eventual não confirmação de suas opiniões pelos demais. Além disso, elas devem ser capazes de equilibrar a defesa de suas opiniões com uma dose semelhante de investigação verdadeira da opinião dos outros. Estas atitudes tendem a gerar um ambiente favorável à participação e aprendizagem mútua coletiva. Infelizmente, segundo as pesquisas destes mesmos autores, o padrão vigente de comunicação entre pessoas na maioria das organizações, gira em torno da emissão de julgamentos atributivos com base em inferências implícitas, pouca referência a dados observáveis, e uso de testes privados quando o assunto trata de questões ameaçadoras. Nesse padrão, há uma ampla predominância de defesa das próprias opiniões em detrimento da investigação verdadeira das opiniões alheias. Tais atitudes tendem a criar um padrão de defensividade entre as pessoas, do tipo "perde-ganha", dificultando assim a criação de um ambiente genuinamente participativo.

Como reflexão final, gostaríamos de considerar que, ainda que modelos normativos como o CMM e CMMI possam ser alvo de investigação de inúmeros pesquisadores, eles são também produtos de mercado. Como tal, eles podem sofrer de problemas como: desatualização, pressão para lançamento de novas versões em função de metas de conquista de mercados, e falta de testes suficientes. Consequentemente, são sujeitos à inconsistências e "bugs" como qualquer produto da indústria de software. Portanto, intervenientes e clientes de programas de MPS devem ter consciência crítica sobre estes aspectos, gerar informação válida e útil sobre sua aplicabilidade e eventuais lacunas em situações específicas, e não tratar o conhecimento preconizado por estes modelos, como verdades incontestáveis.

\section{Algumas Indicações Prescritivas}


São muito vastos os vários aspectos passíveis de análise e recomendações em termos de uma intervenção de MPS, de forma que este texto não intenciona cobri-los todos (se é que isto é possível), nem tampouco alegar que os citados a seguir são necessariamente os mais importantes. O propósito aqui é de enumerar algumas indicações úteis para programas de MPS, à luz das reflexões e conceitos levantados no texto.

Uma estratégia possível, nos moldes do próprio [Argyris, 1970] para geração de informação válida e útil ao longo da intervenção, é a instituição de um grupo de controle para avaliação periódica dos rumos da intervenção, seus pontos fortes, e principalmente identificação e tratamento das barreiras surgidas de diversas naturezas. Este grupo deve ser formado por representantes dos diversos níveis e funções da organização envolvidos no esforço de MPS, ou seja, gerentes sênior, gerentes de projeto, engenheiros de processo, engenheiros de software e possivelmente, até usuários. Este grupo pode ser um poderoso influenciador do comprometimento dos demais participantes.

Nos termos mais específicos de acompanhamento das metas de MPS, pode-se apresentar como outra proposta prática o uso de técnicas de Avaliação de Maturidade de Projetos citadas por [Arent e Iversen, 2000]. Estas técnicas são voltadas para determinar a maturidade de um projeto específico de desenvolvimento de software em relação a um modelo normativo adotado e podem ser um importante instrumento de diagnóstico. Segundo relato destes autores, o uso destas técnicas ao longo de projetos de desenvolvimento de software, inseridos em programas de MPS, além de gerar informação sobre os pontos de melhoria para os projetos, ajudou também na geração do comprometimento com o programa de MPS, tanto do nível gerencial como técnico da organização.

Em termos específicos do fator comprometimento, [Abrahamsson, 2000] sugere que os responsáveis por programas de MPS deveriam priorizar:

- Obtenção de voluntários ao programa (requer a possibilidade de escolha livre).

- Buscar a criação de um ambiente que favoreça o desenvolvimento do comprometimento. (Para isto, seria muito útil buscar um trabalho de desenvolvimento das relações interpessoais que privilegie a educação das habilidades de comunicação das pessoas conforme referido anteriormente nesse texto: comunicar-se referindo-se a dados observáveis, explicitar as inferências e equilibrar a defesa das opiniões próprias com a investigação das teses alheias.)

- Em vez de tentar obter cegamente o mesmo nível de comprometimento de todos, esforçar-se por gerar comprometimento nos stakeholders que tenham mais tendência natural para tal (o que o autor chama de "campeões" de comprometimento) e importância para influenciar os demais. (Para isto, é preciso gerar informação sobre quem são estas pessoas e que extensão de comprometimento pode-se obter delas. Para os demais, segundo o autor, obter aceitação da maioria poderá ser o suficiente para o sucesso do esforço de MPS.)

Considerando a noção de que comprometimento possui um foco e que ele eventualmente pode até ser prejudicial (caso em que há um alto comprometimento, porém vinculado um foco desestruturante para a intervenção), os intervenientes e participantes do esforço de MPS deveriam desenvolver a consciência de que o foco de comprometimento mais desejável é a própria tarefa primária de geração de informação 
válida e útil, já que ela pode subsidiar a consciência crítica e percepção objetiva da necessidade de mudanças no contexto do esforço de MPS.

Um outro ponto importante pode ser proporcionar aos profissionais participantes do programa de MPS, geralmente pessoas de formação preponderantemente técnica, a oportunidade de acessar e praticar conhecimentos oriundos das ciências sociais e organizacionais, úteis ao desenvolvimento do programa.

Finalmente, seria importante que organizações conduzissem intervenções de MPS, conforme sugere [Argyris, 1970], considerando-as em certos aspectos também como uma pesquisa, cujos resultados possam contribuir a este campo de intervenção, gerando conhecimento útil para novas situações.

\section{Considerações Finais e Trabalhos Futuros}

Buscamos aqui, introduzir conceitos de uma teoria de intervenção, que ajudem uma compreensão mais profunda de fenômenos não-técnicos associados a programas de MPS. Mostramos que muitos desses fenômenos tais como comprometimento e participação, considerados críticos pelos resultados de pesquisas na área e pelos próprios modelos normativos de MPS, tendem a ser tratados de forma superficial por estes mesmos modelos. Mostramos ainda, que a maior parte dos fatores críticos de sucesso relatados em MPS são diretamente relacionáveis às tarefas primárias de intervenção sugeridas por [Argyris, 1970]. A utilização de uma teoria de intervenção como esta, para apoiar um programa de MPS, tem como contribuição possibilitar uma melhor concepção, monitoramento e direcionamento destes programas, à luz de conhecimento fundamentado em pesquisa rigorosa, e não apenas em conhecimento tácito ou de senso comum.

Como oportunidades para trabalhos futuros, vislumbramos a possibilidade de definição de um modelo para avaliação (geração de informação válida e útil) de uma intervenção de MPS em andamento, utilizando os conceitos da teoria apresentados neste texto. Não nos referimos aqui a um modelo para avaliação de níveis de maturidade de capacidade de processo ou de projetos, mas sim do andamento e dos rumos da intervenção em si. Este modelo além de ajudar na monitoração das intervenções de MPS, poderia subsidiar pesquisas mais amplas sobre a área.

Uma outra possibilidade interessante, pode ser investigar através de estudos de casos, à luz da teoria de intervenção citada, as possíveis diferenças em programas de MPS, da adoção de modelos normativos contínuos (que parecem mais flexíveis e adaptáveis à escolha livre dos clientes) e por estágios (que parecem mais rígidos).

\section{Referências Bibliográficas}

Abrahamsson, P. Commitment Development in Software Process Improvement: Critical Misconceptions. IEEE Proceedings of the 23rd International Conference on Software Engineering, 2000.

Abrahamsson, P. e livari, N. - Commitment in Software Process Improvement - In Search of the Process - IEEE - Proceedings of the $35^{\text {th }}$ Annual Hawaii International Conference on System Sciences, 2002. 
Arent, J. e Iversen, H. Project Assessments: Supporting Commitment, Participation, and Learning in Software Process Improvement. IEEE Proceedings of the 33rd Hawaii International Conference on System Sciences, 2000.

Argyris, C. e Donald, S. Theory in Practice - Increasing Professional Efectiveness. Addison-Wesley, 1974.

Argyris, C. Intervention Theory and Method: A Behavioral Science View. AddisonWesley, 1970.

Button, G. e Sharrock, W. Occasioned practices in the work of software engineers. Em Jirotka, M. e Goguen, J. Requirements Engineering - Social and Technical Issues. Academic Press, 1994.

CMU/SEI. Capability Maturity Model® Integration (CMMI),Version 1.1 CMU/SEI-, 2001

El Emam, K. Goldenson, D. McCurley e J. Herbsleb, J. Success or Failure? Modeling the Likelihood of Software Process Improvement. International Software Engineering Research Network, 1998.

Fuggetta, A. Software Process: A Roadmap. The Future of Software Engineering, 2000.

Goldenson, D. e Herbsleb, J. After the Appraisal: A Systematic Survey of Process Improvement, its Benefits, and Factors that Influence Success. Technical Report CMU/SEI-95-TR-009, 1995.

Olson, T. Neal, R. Over, J. A Software Process Framework for the SEI Capability Maturity Models. CMU/SEI-94-HB-01, 1994.

Paulk, M. Curtis, B. Chrissis, M. Weber, C. Capability Maturity Model ${ }^{\mathrm{SM}}$ for Software, Version 1.1 Technical Report - CMU/SEI-93-TR-024 ESC-TR-93-177 - February 1993.

Rainer, A. e Hall, T. Key success factors for implementing software process improvement: a maturity-based analysis. Journal of Systems and Software, 2002.

SPICE. Software Process Improvement and Capability dEtermination. Software Quality Institute. http://www.sqi.gu.edu.au/spice/ (último acesso em 17/03/2005).

Stelzer, D. Mellis, W. Success Factors of Organizational Change in Software Process Improvement -Software Process-Improvement and Practice, 1998 - doi.wiley.com.

The Standish Group International, Inc. Extreme Chaos. The Standish Group International, Inc. 2001.

Woolgar, S. Rethinking requirement analysis: Some implications of recent research into producer-consumer relationships in IT development. Em Jirotka, M. e Goguen, J. Requirements Engineering - Social and Technical Issues. Academic Press, 1994. 